\title{
Trusted Sources of COVID-19 Vaccine Information among Hesitant Adopters in the United States
}

\author{
Rachel S. Purvis ${ }^{1}$, Emily Hallgren ${ }^{1}$, Ramey A. Moore ${ }^{1}{ }^{\circledR}$, Don E. Willis $\left.{ }^{1}{ }^{(}\right)$, Spencer Hall ${ }^{2}$, \\ Morgan Gurel-Headley ${ }^{3,4}$ and Pearl A. McElfish ${ }^{1, *(D)}$ \\ 1 College of Medicine, University of Arkansas for Medical Sciences Northwest, 1125 N. College Avenue, \\ Fayetteville, AR 72703, USA; rspurvis@uams.edu (R.S.P.); ehallgren@uams.edu (E.H.); \\ rameymoore@uams.edu (R.A.M.); dewillis@uams.edu (D.E.W.) \\ 2 Office of Community Health and Research, University of Arkansas for Medical Sciences Northwest, \\ 1125 N. College Avenue, Fayetteville, AR 72703, USA; shall@uams.edu \\ 3 College of Medicine, University of Arkansas for Medical Sciences, 4301 W. Markham Street, \\ Little Rock, AR 72205, USA; mpgurel@uams.edu \\ 4 Fay W. Boozman College of Public Health, University of Arkansas for Medical Sciences, \\ 4301 W. Markham Street, Little Rock, AR 72205, USA \\ * Correspondence: pamcelfish@uams.edu
}

check for updates

Citation: Purvis, R.S.; Hallgren, E.; Moore, R.A.; Willis, D.E.; Hall, S.; Gurel-Headley, M.; McElfish, P.A. Trusted Sources of COVID-19 Vaccine Information among Hesitant Adopters in the United States. Vaccines 2021, 9, 1418. https:// doi.org/10.3390/vaccines9121418

Academic Editor: Alessandra Casuccio

Received: 28 October 2021

Accepted: 24 November 2021

Published: 1 December 2021

Publisher's Note: MDPI stays neutral with regard to jurisdictional claims in published maps and institutional affiliations.

Copyright: (c) 2021 by the authors. Licensee MDPI, Basel, Switzerland. This article is an open access article distributed under the terms and conditions of the Creative Commons Attribution (CC BY) license (https:/ / creativecommons.org/licenses/by/ $4.0 /)$.

\begin{abstract}
The World Health Organization has identified vaccine hesitancy as a top health concern. Emerging research shows that those who are hesitant may still get vaccinated; however, little is known about those who say they are hesitant but still get vaccinated. Most people have high trust in several sources of COVID-19 information, and trust in certain information sources such as the Centers for Disease Control and Prevention and health care providers was associated with being vaccinated. This study explored trusted information sources among hesitant adopters in the United States with a survey respondents completed while waiting after receiving a COVID-19 vaccine dose. The study included ( $n=867)$ respondents. The majority of respondents were female $(60.21 \%)$; were between the ages of 18 and 44 years old (71.97\%); and were diverse, with most identifying as White $(44.54 \%)$ or Hispanic/Latinx (32.55\%). Hesitant adopters reported multiple trusted sources of COVID-19 vaccine information, which can be grouped into four emergent subthemes: (1) Health care/Medical science, (2) Personal relationships, (3) News and social media, and (4) Individual/Myself. Some respondents expressed a distrust of all sources of COVID-19 vaccine information, despite receiving the vaccine, describing a lack of trust in traditional sources of information such as the mainstream media or government. This study contributes to the literature by documenting trusted sources of COVID-19 vaccine information among hesitant adopters in the United States. Findings provide important insights about respondents' trusted sources of COVID-19 vaccine information that can inform future public health messaging campaigns intended to increase vaccine uptake among hesitant adopters.
\end{abstract}

Keywords: COVID-19; COVID-19 vaccine; vaccine hesitancy; trusted sources

\section{Introduction}

The Centers for Disease Control and Prevention (CDC) reported the first laboratoryconfirmed case of COVID-19 in the United States (US) in January 2020 [1], and since that time, more than 37,768,911 cases of COVD-19 have been documented in the US [2]. COVID-19 vaccinations began in December 2020 [3], with high demand as early adopters received the vaccine. However, demand slowed [4], and as of August 2021, only 51.5\% of the US is vaccinated [5]. In contrast, the United Arab Emirates and Portugal currently have almost $80 \%$ of their populations vaccinated [6]. Low vaccination rates are often attributed to vaccine hesitancy, with minority communities having the highest levels of vaccine hesitancy and the lowest vaccination rates [7].

The World Health Organization has identified vaccine hesitancy as a top health concern [8]. Vaccine hesitancy is often described as a behavior ranging from refusing to be 
vaccinated to delaying vaccination [9]; however, other scholars see vaccine hesitancy as an attitude that is related to but not synonymous with vaccine behavior [10,11]. Emerging research shows that those who are hesitant may still get vaccinated [12]. Very little is known about those who say they are hesitant but still get vaccinated [13], leaving many questions about "hesitant adopters" unanswered.

Most people have high trust in several sources of COVID-19 information [14]. Furthermore, trust in certain information sources such as the CDC and health care providers was associated with being vaccinated, and those reporting high trust in these sources were more likely to encourage family members and less likely to discourage friends from being vaccinated [14]. Individuals who receive information via traditional media sources such as national television, national newspapers, and local newspapers were most likely to accept the COVID-19 vaccine [15]. US college students reported that trusted information sources play a critical role in predicting vaccine acceptance [16].

No studies have documented the trusted sources of information specifically among hesitant adopters as a distinct population. To encourage uptake among the vaccine-hesitant, it is important to identify their most trusted sources of information about the COVID19 vaccine. This study conducted a mixed-methods examination of trusted sources of information among hesitant adopters in the US.

\section{Methods}

\subsection{Study Design, Aims, and Approach}

The study aimed to understand trusted sources of COVID-19 vaccine information among hesitant vaccine adopters. Data were collected using an online survey to capture quantitative and qualitative data simultaneously [17-23]. All study materials and procedures were approved by the University of Arkansas for Medical Sciences Institutional Review Board (IRB\# 262645) in July 2021.

\subsection{Participant Recruitment}

Potential respondents were recruited in Arkansas between 22 April 2021 and 6 July 2021, from churches, clinics, and community events where the COVID-19 vaccine was being administered. Vaccine sites were selected through our community-engaged collaborative, which is comprised of both researchers and programmatic networks working to implement a COVID-19 Response Strategy to Reduce Health Disparities [24]. Persons over the age of 18 who could read English, Spanish, or Marshallese were invited to participate in the survey. Potential respondents were approached by study staff and provided a sterilized iPad or a study flyer with the QR code link to the survey to complete on their own electronic device. COVID-19 vaccines were provided to all, including those who chose not to participate in the survey.

\subsection{Consent and Remuneration}

Respondent consent and survey responses were captured using REDCap [25]. REDCap is a widely used web-based software created for research data capture and management [25]. Those who completed the survey and provided contact information were entered into a raffle. The raffle consisted of an opportunity to win a $\$ 100$ Wal-Mart gift card. One \$100 Wal-Mart gift card was given out every day that surveys were completed.

\subsection{Data Collection}

Survey responses were obtained while respondents waited the required $15 \mathrm{~min}$ of observation after receiving their COVID-19 vaccine dose. The survey took approximately $10 \mathrm{~min}$ to complete, and the survey was made available to respondents in their preferred language (i.e., English, Spanish, or Marshallese). Bilingual study staff translated text responses for open-ended survey items provided in Spanish or Marshallese to English. 


\subsection{Instruments}

Survey items were selected from validated sources that are part of the PhenX Toolkit [26]. The survey captured socioeconomic demographics, including age, sex, race/ethnicity, education, marital status, and employment status using questions from the Behavioral Risk Factor Survey [27]. Vaccine hesitancy was assessed using a single-item measure of general vaccine hesitancy that we modified [11,28]. Respondents were asked, "Thinking specifically about the COVID-19 vaccine, how hesitant were you about getting vaccinated?" To answer, respondents selected one of these options: "Not at all hesitant", "A little hesitant", "Somewhat hesitant", "Very hesitant", and "Prefer not to answer". To understand trusted sources of information among hesitant adopters, respondents were asked the open-ended question, "When deciding whether or not to get the vaccine, what sources of information did you trust the most?" To determine what sources of information they were likely to turn to about the COVID-19 vaccine, participants were asked to select the likelihood they would rely on "a doctor, nurse, or other health care provider", "family or friends", "The Centers for Disease Control and Prevention, also known as the CDC", "Your state or local public health department", "A pharmacist", "A religious leader such as minster, pastor, priest, or rabbi", and "Social media (e.g., Facebook, Twitter, YouTube, WhatsApp)". Respondents could answer by selecting from response options for each source that included "Very likely", "Somewhat likely", "Not too likely", "Not at all likely", and "Prefer not to answer".

\subsection{Study Sample}

A total of 1475 valid responses to the survey were collected between 22 April 2021 and 6 July 6 2021. Of those, 1452 provided a response to the question on COVID-19 vaccine hesitancy. A total of 867 respondents reported being hesitant when getting their COVID-19 vaccination. These "hesitant adopters" comprise the analytic sample with participants: "very hesitant $(n=150)$ ", "somewhat hesitant $(n=269)$ ", or "a little hesitant $(n=448)$ ". Respondents who selected "prefer not to answer" were excluded.

\subsection{Data Analysis}

Respondent characteristics and the likelihood of respondents to turn to specific sources of information about the COVID-19 vaccine were tabulated and provided as descriptive summaries. To analyze open-ended items, a qualitative descriptive approach was used to summarize and synthesize respondents' experiences and perceptions as well as the meanings that respondents attributed to them [29]. MAXQDA 2020 was used to analyze and categorize data into primary themes [30]. Three researchers with qualitative expertise reviewed all responses and developed a codebook with emergent primary themes and subthemes. Data segments were coded, the first author developed the categories, and two additional qualitative researchers performed confirmation-coding analysis. As codes were refined, the codebook was revised three times. The research team critically reviewed each analysis summary to ensure that the data and illustrative excerpts were extracted to the appropriate thematic domain and to ensure analytic rigor and reliability. Any divergences in data interpretation were discussed by the research team and resolved via consensus. The most illustrative quotes were identified under each thematic domain. Many statements are interrelated and expressed within the same sentence, and quotes are presented within the themes they represent best. After codes were finalized, MAXQDA was used to generate the frequency of each primary code among 867 responses. The frequency of each theme is presented.

\section{Results}

Table 1 presents descriptive statistics for age, sex, race/ethnicity, education, marital status, and employment status. The majority of respondents were female $(60.21 \%)$ and between the ages of 18 and 44 years old $(71.97 \%)$. Respondents were diverse with most identifying as White (44.54\%) or Hispanic/Latinx (32.55\%); $8.46 \%$ identified as Native 
Hawaiian or Pacific Islander, $6.46 \%$ as Black/African American, $4.70 \%$ as Asian, $2.35 \%$ as Multiracial, and $0.94 \%$ as American Indian/Alaska Native. Just over half of respondents said they were not married (52.63\%). A majority of respondents reported they had some college or a four-year degree or more $(61.67 \%)$. Half of the respondents said they were employed full-time $(50.61 \%)$. The sample is diverse by race and ethnicity; however, the sample is over-representative of women, and a disproportionate amount of respondents reported a four-year degree (37.86\%) than the overall state population reporting a four-year degree $(32.10 \%)$ in the state of Arkansas [31].

Table 1. Descriptive characteristics of recently vaccinated Arkansans $(n=867)$.

\begin{tabular}{|c|c|c|}
\hline & Frequency & $\%$ or $\bar{x}$ \\
\hline Age & 867 & 37.21 \\
\hline $18-24$ & 178 & $20.53 \%$ \\
\hline $25-34$ & 219 & $25.26 \%$ \\
\hline $35-44$ & 227 & $26.18 \%$ \\
\hline $45-54$ & 136 & $15.69 \%$ \\
\hline $55-64$ & 84 & $9.69 \%$ \\
\hline $65+$ & 23 & $2.65 \%$ \\
\hline Sex & 862 & \\
\hline Female & 519 & $60.21 \%$ \\
\hline Male & 343 & $39.79 \%$ \\
\hline Race/Ethnicity & 851 & \\
\hline American Indian/Alaska Native & 8 & $0.94 \%$ \\
\hline Asian & 40 & $4.70 \%$ \\
\hline Black/African American & 55 & $6.46 \%$ \\
\hline Native Hawaiian or Pacific Islander & 72 & $8.46 \%$ \\
\hline White & 379 & $44.54 \%$ \\
\hline Hispanic/Latinx & 277 & $32.55 \%$ \\
\hline Multiracial & 20 & $2.35 \%$ \\
\hline Education & 840 & \\
\hline Less than High School & 110 & $13.10 \%$ \\
\hline High School or GED & 212 & $25.24 \%$ \\
\hline Some College & 200 & $23.81 \%$ \\
\hline Four-Year Degree or More & 318 & $37.86 \%$ \\
\hline Marital Status & 838 & \\
\hline Married & 397 & $47.37 \%$ \\
\hline Not Married & 441 & $52.63 \%$ \\
\hline Employment Status & 816 & \\
\hline Full Time & 413 & $50.61 \%$ \\
\hline Part Time & 82 & $10.05 \%$ \\
\hline Other & 321 & $39.34 \%$ \\
\hline COVID-19 Vaccine Hesitancy & 867 & \\
\hline A Little Hesitant & 448 & $51.67 \%$ \\
\hline Somewhat Hesitant & 269 & $31.03 \%$ \\
\hline Very Hesitant & 150 & $17.30 \%$ \\
\hline
\end{tabular}

Within the quantitative options, hesitant adopters reported the likelihood they would turn to seven sources for information about the COVID-19 vaccine (Table 2). Almost two-thirds of respondents $(64.88 \%)$ said they were 'very likely' to turn to a health care provider for information about the vaccine, and over half (51.87\%) were 'very likely' to use the $\mathrm{CDC}$ for vaccination information. Respondents were also 'very likely' to turn to family $(42.64 \%)$, the health department $(40.88 \%)$, or a pharmacist (37.95\%) for COVID-19 vaccine information. Some respondents $(18.86 \%)$ said they were 'very likely' to turn to a religious leader for COVID-19 vaccination information. Finally, some respondents $(15 \%)$ reported they were 'very likely' to turn to social media for COVID-19 vaccine information. 
Table 2. Likelihood of turning to information sources when deciding whether to get a COVID-19 vaccine among hesitant adopters.

\begin{tabular}{cccccc}
\hline & Very Likely & Somewhat Likely & Not too Likely & Not at All Likely & PNA * \\
\hline Health Care Provider & $558(64.88 \%)$ & $210(24.42 \%)$ & $54(6.28 \%)$ & $23(2.67 \%)$ & $15(1.74 \%)$ \\
CDC & $444(51.87 \%)$ & $251(29.32 \%)$ & $89(10.40 \%)$ & $55(6.43 \%)$ & $17(1.99 \%)$ \\
Family & $368(42.64 \%)$ & $318(36.85 \%)$ & $130(15.06 \%)$ & $35(4.06 \%)$ & $12(1.39 \%)$ \\
Health Department & $352(40.88 \%)$ & $331(38.44 \%)$ & $106(12.31 \%)$ & $56(6.50 \%)$ & $16(1.86 \%)$ \\
Pharmacist & $326(37.95 \%)$ & $274(31.90 \%)$ & $164(19.09 \%)$ & $77(8.96 \%)$ & $18(2.10 \%)$ \\
Religious Leader & $162(18.86 \%)$ & $176(20.49 \%)$ & $173(20.14 \%)$ & $320(37.25 \%)$ & $28(3.26 \%)$ \\
Social Media & $129(15.00 \%)$ & $153(17.79 \%)$ & $222(25.81 \%)$ & $337(39.19 \%)$ & $19(2.21 \%)$ \\
\hline
\end{tabular}

* Note: Prefer Not to Answer (PNA).

Within the qualitative data, hesitant adopters reported multiple sources of trusted information about the COVID-19 vaccine. Trusted sources of vaccine information can be grouped into four emergent subthemes: (1) Health care/Medical science (50.2\%), (2) Personal relationships (21.8\%), 3) News and social media (16.4\%), and 4) Individual/Myself (4.2\%). These categories represent $92.5 \%$ of the coded responses related to trusted sources of information about the COVID-19 vaccine. Some hesitant adopters reported they did not trust any sources of information (7.5\%), describing a lack of trust in traditional sources of information like the mainstream news media or government. Table 3 presents definitions and examples for each emergent subtheme, and Figure 1 provides a Word Cloud representation of respondents' trusted sources of information.

Table 3. Primary themes and emergent subthemes with definitions and examples.

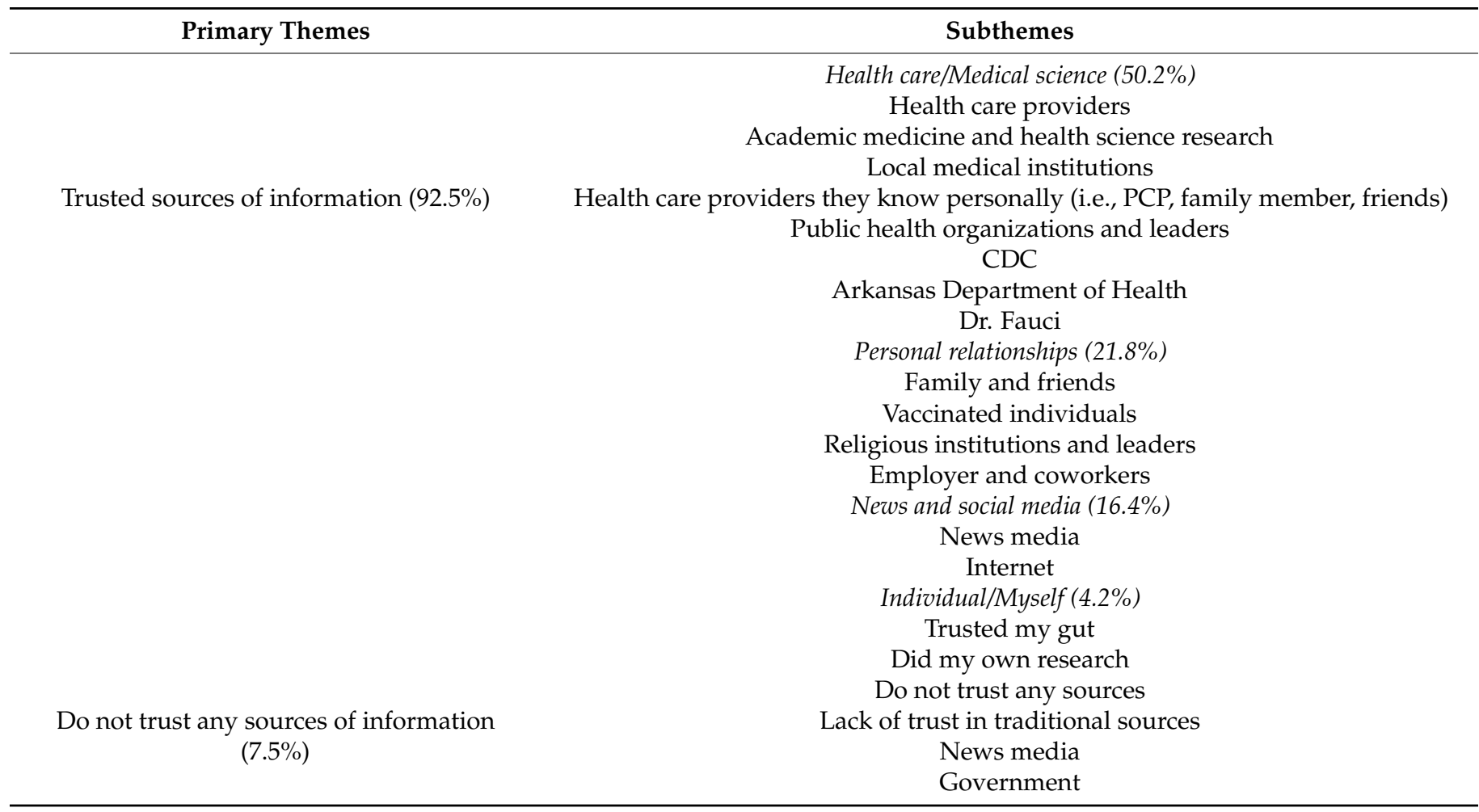




\section{hospital friend science professional wife government family mom tv research scientist church physician NWW internet fauci uams

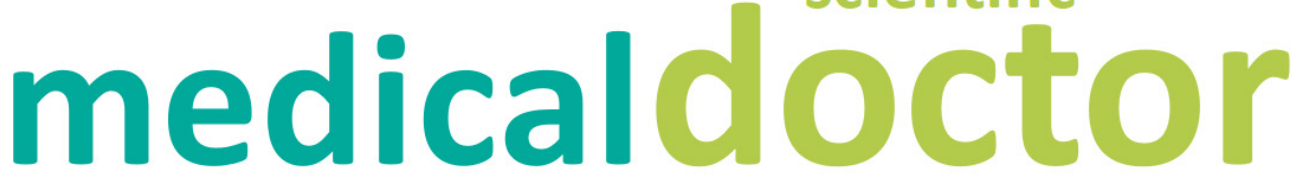

Figure 1. Word Cloud representation of trusted sources of information about COVID-19 vaccine.

\subsection{Trusted Sources of Information}

\subsubsection{Health Care/Medical Science}

Over half of respondents (50.2\%) described health care and medical science sources as their trusted source of information about the COVID-19 vaccine. Within the primary theme of health care providers/medical science, respondents reported two specific sources they trusted for vaccination information: (1) Health care providers (36.3\%) and (2) Public health organizations and leaders (13.9\%).

\section{Health Care Providers}

Respondents reported a range of health care providers they considered a trusted source of COVID-19 vaccine information, including academic medicine and health science research, local medical institutions, and health care providers they know personally.

When describing academic medicine and health science research, most respondents said "science", "scientists", or "research". One respondent said, "I trusted the scientists that they would not have put it on the market if it wasn't safe". Another reported, "The sources of medical information that I trust the most would be scientists and medical staff that know more information about this virus". Other respondents said they trusted "recent research articles", "legitimate reports of efficacy", and "scientific papers in recognized journals".

Respondents also reported local medical institutions and hospitals as trusted sources of information about the COVID-19 vaccine, stating, "hospital" or "UAMS [University of Arkansas for Medical Sciences, the state's only academic medical center]". Respondents reported, "Actual hospitals", "hospital websites", and "information directly from hospitals". One respondent said, "I trusted the people I called at UAMS". Other respondents stated they trusted "employees" and "information given at the local academic medical center".

Respondents reported health care providers as a trusted source of information, with most stating "doctors", "nurses", or "doctors and medical field professionals". Respondents also reported health care providers they know personally (i.e., primary care physician, family members, friends) as trusted sources of information about the COVID-19 vaccine. One respondent said, "My personal doctor. He confirmed that it was a safe and best way to go about the virus". Another respondent said, "I talked to my doctor and he highly recommended it". Other respondents reported, "My primary care doctor and specialized doctor", "medical doctors, pharmacists, and nurses", and "medical professionals I know 
and trust". Other respondents stated family members or friends in the health care field were trusted sources of COVID-19 vaccine information. A respondent said, "My mother who was a nurse for many years, her friends who have studied viruses. Those who work in the medical fields and that I know personally". Other respondents reported, "Medical doctor and trusted health care friends", "friends and family in the medical field", and "friends with medical expertise". Other respondents said, "My wife, she's a nurse", "nurse in my family", and "my mother, a nurse".

Public Health Organizations and Leaders

When describing public health organizations and leaders, respondents consistently reported the CDC, Arkansas Department of Health, and Dr. Anthony Fauci [Director of National Institute of Allergy and Infectious Diseases] as trusted sources of COVID-19 vaccine information. The majority of respondents simply stated, "CDC", "health department", or "Dr. Fauci" when discussing public health organizations and leaders as trusted sources. One respondent said, "Dr. Fauci and other scientist of world leaders pushed me to do this". Another respondent echoed this: "Dr. Fauci. I trust him more than any other public figure and value his years of experience and service to our country". Other respondents stated, "Information from the CDC", "CDC and any department of health", and "the CDC has provided very great information about how the vaccine works".

\subsubsection{Personal Relationships}

A significant number of respondents (21.8\%) described personal relationships as their trusted source of information about the COVID-19 vaccine in their open-ended responses. A respondent explained, "I have considerably more trust in the educated opinions of people I know". Within this primary theme, respondents reported four specific sources they trusted for vaccination information: (1) Family and friends (16.7\%), (2) Vaccinated individuals (2.0\%), (3) Religious institutions and leaders (2.6\%), and (4) Employers and coworkers $(0.5 \%)$.

Family and Friends

When describing family and friends as trusted sources of information, respondents typically said, "my family" or "my friends". A respondent reported, "Information from my parents". Another said, "I got my information from family and friends" and "I mostly trusted my parents". Others said, "My sister and my husband" and "my mom". Merging into another theme, respondents explained that family and friends who had already received their vaccine were their trusted source of information. One respondent reported, "Family members and friends who have been vaccinated. It was helpful to hear a variety of symptoms and experience with the vaccine". Another respondent said, "Previous family members receiving it and them being okay with it". Others said, "Friends who had taken the vaccine already" and "I asked friends and family that have gotten the vaccine about the symptoms".

\section{Vaccinated Individuals}

Some respondents discussed vaccinated individuals generally as a trusted source of information. A respondent said, "I really trusted people who had already gotten the vaccine". Another respondent stated, "People that have gotten the vaccine before me". Respondents reported, "Personal experiences of people I know", "Other people's experiences", and "In the experiences of those who have already gotten vaccinated". One respondent reported, "Just observing the ones that had it done" as a trusted source of information about the COVID-19 vaccine.

\section{Religious Institutions and Leaders}

While the proportion was lower than many other responses, respondents also identified religious institutions and leaders as trusted sources of information. When dis- 
cussing religious institutions and leaders, respondents said "the church" or "my church". One respondent reported that "the information that they gave us at the church" was a trusted source. Another respondent said, "My church sent out an email with some information which also helped me tremendously". Others reported, "Trusted ecclesiastical leaders", "The priest of the church", and "the information that the church is giving" as trusted sources.

\section{Employer and Coworkers}

A small number of respondents $(0.5 \%)$ reported their employer and coworkers as trusted sources of COVID-19 vaccine information. One respondent said, "My job provided information". Another respondent said, "Updated information provided by JB Hunt". Other respondents reported "Work" or "Coworkers" as trusted sources of vaccination information.

\subsubsection{News and Social Media}

Some respondents $(16.4 \%)$ reported news and social media as trusted sources of information about the COVID-19 vaccine in their open-ended responses. Within this theme, respondents reported two specific sources: (1) News media (9.1\%) and (2) Internet (7.3\%).

News Media

When describing news media sources they trusted for information, respondents typically said "the news", "newspapers", "creditable news", or "the radio". Other respondents reported, "MSNBC and CNN", "PBS", "Local news", and "Fox News" as trusted sources of vaccine information.

Internet

Respondents also reported online sources they trusted for COVID-19 vaccine information. One respondent said, "Science websites". Others said, "Medical online sources", "official medical websites", and "credible online sources such as CDC.gov". Another respondent stated they trusted "Independent leftist news sources on YouTube, Instagram, and Facebook". One respondent reported, "Local news website and social media page that links to healthcare pages" as trusted sources. Respondents also reported simply, "online sources", "websites", "Facebook", "Google", and the "internet".

\subsubsection{Individual/Myself}

A few respondents (4.2\%) reported themselves as a trusted source of COVID-19 information in their open-ended responses. Within this theme, respondents discussed two specific sources they trusted for information: (1) Trusted my gut and (2) Did my own research.

\section{Trusted My Gut}

A respondent reported, "I trusted my gut and intuition" for vaccine information. Another respondent said, "Really just trusting my gut". Other respondents said, "Just myself", "Me", or "my gut" were trusted sources.

\section{Did My Own Research}

A few respondents said they trusted their own research as a trusted source of information about the COVID-19 vaccine. One respondent reported, "I read some articles on the Pfizer vaccine". Another respondent said, "Doing research on it" and "cross-referencing multiple sites and facts". One respondent stated, "I conducted my own research", and another respondent reported, "I used Google to find trustworthy news sources on the various vaccines to determine which one to get". 


\subsection{Do Not Trust Any Sources of Information}

Almost one in ten respondents (7.5\%) discussed distrust or a lack of trust in sources for information about the COVID-19 vaccine in their open-ended responses. Within this primary theme, respondents reported two subthemes: (1) Do not trust any sources and (2) Lack of trust in traditional sources.

\subsubsection{Do Not Trust Any Sources}

One respondent reported, "None. So much conflicting information". Another respondent said, "None of it. I don't believe in the vaccine at all. It is just an untested glorified flu shot to me". A respondent stated, "All of this was bull shit. Everything contradicted each other or even themselves. I have zero faith in any of this". Other respondents said, "Not any", "None at all", and "Nothing".

\subsubsection{Lack of Trust in Traditional Sources}

A few respondents reported they lacked trust in traditional sources of information such as the news media or government. A respondent explained, "I don't feel that there are many unbiased media sources". Another respondent said, "No sources as I don't trust the news or government". Others said, "Not the news since the double or the single shot are more or less experimental", and "Definitely not the media". Another respondent said, "Allow me to answer the opposite question: I have little to no trust in mass media".

\section{Discussion}

This study documents the trusted sources of information among hesitant adopters as well as a lack of trust in traditional sources of information about the COVID-19 vaccine using quantitative and qualitative methods. Respondents reported health care and medical science sources as their trusted source of information about the COVID-19 vaccine as the most frequent option in both the qualitative and quantitative data. State and federal public health organizations and leaders were also reported as trusted sources of COVID-19 vaccine information. These findings are consistent with prior research that documents high levels of trust in health care providers [32] and the CDC [33-35] as sources of general COVID-19 information. This data also supports previous findings of high levels of trust for scientists, health departments, and health professionals as sources of information about the COVID-19 vaccine $[14,16,36]$. While some studies suggest that there has been a decline in trust of health care providers and organizations as sources of information related to COVID-19 [35,37-39], our study and others [33-35] document that health care providers and organizations are the greatest sources of trusted information regarding COVID-19, including among hesitant adopters.

Respondents described personal relationships-family and friends, religious institutions and leaders, employers, and coworkers-as trusted sources of vaccine information. Respondents described how personal testimonies from vaccinated individuals about their experiences were also a trusted source of information. This notable finding demonstrates the importance of personal testimonies of vaccination experiences that could inform public health messaging campaigns to increase vaccine uptake. This finding is consistent with research that has documented social relationships as a primary influence of vaccination uptake [40]. The qualitative responses demonstrated that health care providers who respondents knew personally were an important trusted source of information. These sources were described as having both expertise and a valued social connection. This overlap of personal relationships with specific expertise may increase perceptions of trustworthiness.

A few respondents reported the news media and internet as trusted sources of COVID19 vaccine information [35,37-39]. While historically news media such as national and local television, newspapers, and radio have been important sources of health information $[37,41,42]$, a 2020 study $(n=10,139)$ reported that less than half of US adults $(49 \%)$ said the news media's coverage of COVID-19 has been largely accurate [43,44]. Our study results are consistent with previous findings showing that the news media is often seen as less 
trustworthy when compared to other sources of information about COVID-19 [34,35,37] and the COVID-19 vaccine specifically [14,36].

Some respondents expressed a distrust of all sources of information about the COVID19 vaccine, even though they had received the vaccine. Among those who cited a lack of trust, several respondents described not trusting traditional sources of information, such as the mainstream media and government. These findings are consistent with previous studies documenting a decline in Americans' trust in COVID-19 information provided by the news media and federal and state governments $[38,39,43]$.

\subsection{Strengths and Limitations}

The study is not without limitations. Survey respondents were recruited as they waited the required fifteen minutes after receiving their COVID-19 vaccine dose, so this non-random sample may not be representative of the general populations of Arkansas or the US. The study sample size was not pre-determined, and all people who participated in the survey were included. Respondents who reported some level of vaccine hesitancy and who got the COVID-19 vaccine comprised the study sample. Generalizability is improved because the sample is large and diverse. It is not known to what degree respondents were exposed to different modes of information, and this limits comparative analysis. Openended questions allowed respondents to provide their typed responses anonymously and to describe their perceptions of trusted sources of COVID-19 vaccine information in their own words; however, the research team lacked the opportunity to probe for clarification of respondents' typed responses. Despite these limitations, this study documents trusted sources of information among hesitant adopters and provides important information that can be used to improve health messaging and increase vaccine uptake among those who are hesitant.

\subsection{Recommendations and Implications for Practice}

This study documents trust in health care and personal relationships as sources of information about the COVID-19 vaccine. Respondents reported being very likely to turn to a health care provider, the $C D C$, and family as sources of information when deciding if they will get vaccinated. In particular, respondents said that hearing about the experiences of people who were vaccinated was a trusted source of COVID-19 vaccine information. Personal testimony from those who are vaccinated, such as local health care providers or community members, could be important to marketing campaigns intended to increase vaccine uptake. Future research should examine trusted sources among hesitant nonvaccinated individuals to identify additional factors that may encourage vaccine uptake.

\section{Conclusions}

This study makes an important contribution to the literature as the first mixed-methods study on trusted sources of COVID-19 vaccine information among hesitant adopters. The study documents trusted sources of vaccine information among hesitant adopters, such as health care providers, family and friends, and vaccinated individuals. The study also documents a lack of trust in traditional sources of information including the news media and the government. These findings provide important insights about respondents' trusted sources of COVID-19 vaccine information that can inform future public health messaging campaigns intended to increase vaccine uptake among hesitant adopters.

Author Contributions: Conceptualization, D.E.W. and P.A.M.; Methodology, D.E.W. and P.A.M.; Validation, E.H., R.A.M., D.E.W. and M.G.-H.; Formal Analysis, R.S.P. and S.H.; Resources, P.A.M.; Data Curation, D.E.W. and S.H.; Writing-Original Draft Preparation, R.S.P.; Writing-Review \& Editing, E.H., R.A.M., D.E.W., S.H., M.G.-H. and P.A.M.; Visualization, R.S.P. and S.H.; Supervision, P.A.M.; Project Administration, P.A.M.; Funding Acquisition, P.A.M. All authors have read and agreed to the published version of the manuscript. 
Funding: The community engagement related to this research is supported by the University of Arkansas for Medical Sciences Translational Research Institute funding awarded through the National Center for Research Resources and National Center for Advancing Translational Sciences of the National Institutes of Health (NIH) (UL1 TR003107); Rapid Acceleration of Diagnostics (RADx) (NIH 3 R01MD013852-02S3); and Community Engagement Alliance (CEAL) Against COVID-19 Disparities (NIH 10T2HL156812-01). The content is solely the responsibility of the authors and does not necessarily represent the official views of the NIH.

Institutional Review Board Statement: All study materials and procedures were approved by the University of Arkansas for Medical Sciences Institutional Review Board (IRB\# 262645).

Informed Consent Statement: Respondent consent and survey responses were captured using REDCap, a widely used web-based software created for research data capture and management.

Data Availability Statement: The deidentified data underlying the results presented in this study may be made available upon reasonable request from the corresponding author, Dr. Pearl A. McElfish, at pamcelfish@uams.edu. The data are not publicly available in accordance with funding requirements and participant privacy.

Conflicts of Interest: The authors declare no conflict of interest.

\section{References}

1. Stokes, E.K.; Zambrano, L.D.; Anderson, K.N.; Marder, E.P.; Raz, K.M.; El Burai Felix, S.; Tie, Y.; Fullerton, K.E. Coronavirus Disease 2019 Case Surveillance-United States, 22 January-30 May 2020. MMWR Morb. Mortal. Wkly. Rep. 2020, 69, 759-765. [CrossRef]

2. Centers for Disease Control and Prevention. CDC COVID Data Tracker. Available online: https:/ / covid.cdc.gov / covid-datatracker/\#cases_casesper100klast7days (accessed on 24 August 2021).

3. Hughes, M.M.; Wang, A.; Grossman, M.K.; Pun, E.; Whiteman, A.; Deng, L.; Hallisey, E.; Sharpe, J.D.; Ussery, E.N.; Stokley, S.; et al. County-Level COVID-19 Vaccination Coverage and Social Vulnerability-United States, 14 December 2020-1 March 2021. MMWR Morb. Mortal. Wkly. Rep. 2021, 70, 431-436. [CrossRef]

4. Hassan, A.; Weiland, N. Some Mass Vaccination Sites in U.S. Close as Demand Begins to Fall. The New York Times. 23 April 2021. Available online: https://www.nytimes.com/2021/04/23/us/some-mass-vaccination-sites-in-us-close-as-demand-begins-tofall.html (accessed on 15 September 2021).

5. Centers for Disease Control and Prevention. COVID-19 Vaccinations in the United States. Available online: https://covid.cdc. gov/covid-data-tracker/\#vaccinations (accessed on 24 August 2021).

6. Ritchie, H.; Mathieu, E.; Rodes-Guirao, L.; Appel, C.; Giattino, C.; Ortiz-Ospina, E.; Hasell, J.; Macdonald, B.; Beltekian, D.; Roser, M. Coronavirus Pandemic (COVID-19). Our World in Data, 2020. Available online: https://ourworldindata.org/covidvaccinations (accessed on 15 September 2021).

7. Willis, D.E.; Andersen, J.A.; Bryant-Moore, K.; Selig, J.P.; Long, C.R.; Felix, H.C.; Curran, G.M.; McElfish, P.A. COVID-19 vaccine hesitancy: Race/ethnicity, trust, and fear. Clin. Transl. Sci. 2021, 14, 2200-2207. [CrossRef] [PubMed]

8. World Health Organization. Ten Threats to Global Health in 2019. Available online: https://www.who.int/vietnam/news/ feature-stories / detail/ten-threats-to-global-health-in-2019 (accessed on 24 August 2021).

9. MacDonald, N.E. Vaccine hesitancy: Definition, scope and determinants. Vaccine 2015, 33, 4161-4164. [CrossRef]

10. Dubé, E.; Laberge, C.; Guay, M.; Bramadat, P.; Roy, R.; Bettinger, J. Vaccine hesitancy: An overview. Hum. Vaccines Immunother. 2013, 9, 1763-1773. [CrossRef] [PubMed]

11. Quinn, S.C.; Jamison, A.M.; An, J.; Hancock, G.R.; Freimuth, V.S. Measuring vaccine hesitancy, confidence, trust and flu vaccine uptake: Results of a national survey of White and African American adults. Vaccine 2019, 37, 1168-1173. [CrossRef]

12. Kirzinger, A.; Sparks, G.; Brodie, M. KFF COVID-19 Vaccine Monitor: In Their Own Words, Six Months Later. Available online: https://www.kff.org/coronavirus-covid-19/poll-finding/kff-covid-19-vaccine-monitor-in-their-own-words-six-monthslater / (accessed on 24 August 2021).

13. Enkel, S.; Attwell, K.; Snelling, T.; Christian, H. 'Hesitant compliers': Qualitative analysis of concerned fully-vaccinating parents. Vaccine 2018, 36, 6459-6463. [CrossRef]

14. Latkin, C.A.; Dayton, L.; Miller, J.R.; Yi, G.; Jaleel, A.; Nwosu, C.C.; Yang, C.; Falade-Nwulia, O. Behavioral and Attitudinal Correlates of Trusted Sources of COVID-19 Vaccine Information in the US. Behav. Sci. 2021, 11, 56. [CrossRef]

15. Piltch-Loeb, R.; Savoia, E.; Goldberg, B.; Hughes, B.; Verhey, T.; Kayyem, J.; Miller-Idriss, C.; Testa, M. Examining the effect of information channel on COVID-19 vaccine acceptance. PLoS ONE 2021, 16, e0251095. [CrossRef] [PubMed]

16. Qiao, S.; Friedman, D.B.; Tam, C.C.; Zeng, C.; Li, X. Vaccine acceptance among college students in South Carolina: Do information sources and trust in information make a difference? medRxiv 2020. [CrossRef]

17. Bergman, M. Advances in Mixed Methods Research: Theories and Applications; SAGE Publications Ltd.: London, UK, 2008.

18. Creswell, J.W. Research Design: Qualitative, Quantitative, and Mixed Methods Approaches, 4th ed.; SAGE: Thousand Oaks, CA, USA, $2013 ;$ p. 273. 
19. Creswell, J.W.; Plano Clark, V.L. Designing and Conducting Mixed Methods Research, 2nd ed.; SAGE: Thousand Oaks, CA, USA, 2010; p. 488.

20. Creswell, J.; Plano Clark, V.; Gutmann, M.; Hanson, W. Advanced mixed methods research designs. In Handbook of Mixed Methods in Social and Behavioral Research; Tashakkori, A., Teddlie, C., Eds.; SAGE: Thousand Oaks, CA, USA, 2003; pp. $209-240$.

21. Johnson, R.; Onweugbuzie, A.; Turner, L. Toward a definitions of mixed methods research. J. Mix. Methods Res. 2007, 1, 112-133. [CrossRef]

22. Johnson, R.; Onwuegbuzie, A. Mixed methods research: A research paradigm whose time has come. Educ. Res. 2004, 33, 14-26. [CrossRef]

23. Sale, J.E.; Lohfeld, L.H.; Brazil, K. Revisiting the Quantitative-Qualitative Debate: Implications for Mixed-Methods Research. Qual. Quant. 2002, 36, 43-53. [CrossRef] [PubMed]

24. McElfish, P.; Cleek, A.; Willis, D.; Purvis, R.; James, L. Leveraging community engagement capacity to address COVD-19 disparities among Pacific Islander and Latinx Communities in Arkansas. J. Clin. Transl. Sci. 2020, 5, e81. [CrossRef]

25. Harris, P.; Taylor, R.; Thielke, R.; Payne, J.; Gonzalez, N.; Conde, J. Research electronic data capture (REDCap)—A metadata-driven methodology and workflow process for providing translational research informatics support. J. Biomed. Inform. 2009, 42, 377-381. [CrossRef]

26. PhenX Toolkit. PhenX Toolkit: News. Available online: https://www.phenxtoolkit.org/news/statistics (accessed on 15 April 2021).

27. Centers for Disease Control and Prevention. 2019 BRFSS Questionnaire. Available online: https://www.cdc.gov/brfss/ questionnaires / pdf-ques/2019-BRFSS-Questionnaire-508.pdf (accessed on 5 May 2021).

28. Quinn, S.C.; Jamison, A.; Freimuth, V.S.; An, J.; Hancock, G.R.; Musa, D. Exploring racial influences on flu vaccine attitudes and behavior: Results of a national survey of White and African American adults. Vaccine 2017, 35, 1167-1174. [CrossRef] [PubMed]

29. Neergaard, M.A.; Olesen, F.; Andersen, R.S.; Sondergaard, J. Qualitative description-The poor cousin of health research? BMC Med. Res. Methodol. 2009, 9, 52. [CrossRef] [PubMed]

30. Kuckartz, U.; Radiker, S. Analyzing Qualitative Data with MAXQDA; Springer: Basel, Switzerland, 2019.

31. United States Census Bureau. QuickFacts: Arkansas. United States. Available online: https://www.census.gov/quickfacts/fact/ table/AR,US/PST045219 (accessed on 7 October 2021).

32. Earnshaw, V.; Eaton, L.; Kalichman, S.; Brousseau, N.; Hill, E.; Fox, A. COVID-19 conspiracy beliefs, health behaviors, and policy support. Transl. Behav. Med. 2020, 10, 850-856. [CrossRef]

33. McFadden, S.M.; Malik, A.A.; Aguolu, O.G.; Willebrand, K.S.; Omer, S.B. Perceptions of the adult US population regarding the novel coronavirus outbreak. PLOS ONE 2020, 15, e0231808. [CrossRef]

34. Fridman, I.; Lucas, N.; Henke, D.; Zigler, C.K. Association Between Public Knowledge About COVID-19, Trust in Information Sources, and Adherence to Social Distancing: Cross-Sectional Survey. JMIR Public Health Surveill. 2020, 6, e22060. [CrossRef]

35. Boyle, J.; Brassell, T.; Dayton, J. Who Do Americans Trust for COVID-19 News and Information? ICF International, 2020. Available online: https: / / www.icf.com/insights/health/covid-19-public-health-findings-mitigation (accessed on 15 September 2021).

36. Malik, A.A.; McFadden, S.M.; Elharake, J.; Omer, S.B. Determinants of COVID-19 vaccine acceptance in the US. EClinicalMedicine 2020, 26, 100495. [CrossRef] [PubMed]

37. Ali, S.H.; Foreman, J.; Tozan, Y.; Capasso, A.; Jones, A.M.; DiClemente, R.J. Trends and Predictors of COVID-19 Information Sources and Their Relationship With Knowledge and Beliefs Related to the Pandemic: Nationwide Cross-Sectional Study. JMIR Public Health Surveill. 2020, 6, e21071. [CrossRef] [PubMed]

38. Boyle, J.; Brassell, T.; Dayton, J. American Trust in COVID-19 Information from Federal and State/Local Government Is Trending Downward. ICF International, 2020. Available online: https: / www.icf.com/insights/health/covid-19-survey-trustgovernment-response-erodes (accessed on 15 September 2021).

39. Boyle, J.; Brassell, T.; Dayton, J. As Cases Increase, American Trust in COVID-19 Information from Federal, State, and Local Governments Continues to Decline. ICF International, 2020. Available online: https://www.icf.com/insights/health/covid-19 -survey-american-trust-government-june (accessed on 15 September 2021).

40. Brewer, N.; Chapman, G.; Rothman, A.; Leask, J.; Kempe, A. Increasing Vaccination: Putting Psychological Science Into Action. Psychol. Sci. Public Interest 2017, 18, 149-207. [CrossRef] [PubMed]

41. Henrich, N.; Holmes, B. Communicating during a pandemic: Information the public wants about the disease and new vaccines and drugs. Health Promot. Pract. 2011, 12, 610-619. [CrossRef] [PubMed]

42. Wong, L.; Sam, I. Public sources of information and information needs for pandemic influenza A(H1N1). J. Community Health 2010, 35, 676-682. [CrossRef]

43. Pew Research Center. Americans' Views of the News Media During COVID-19 Outbreak. Pew Research Center, 8 May 2020. Available online: https:/ / www.journalism.org/2020/05/08/americans-views-of-the-news-media-during-the-covid-19 - outbreak/ (accessed on 15 September 2021).

44. Mitchell, A.; Oliphant, J. Americans Immersed in COVID-19 News; Most Think Media Are Doing Fairly Well Covering It; Pew Research Center: 18 March 2020. Available online: https://www.pewresearch.org/journalism/2020/03/18/americansimmersed-in-covid-19-news-most-think-media-are-doing-fairly-well-covering-it/ (accessed on 15 September 2021). 